\title{
Sjogren-Larsson Syndrome
}

National Cancer Institute

\section{Source}

National Cancer Institute. Sjogren-Larsson Syndrome. NCI Thesaurus. Code C85070.

An autosomal recessive condition caused by mutation(s) in the ALDH3A2 gene, encoding fatty aldehyde dehydrogenase. It is a characterized by dry and scaly skin, neurological dysfunction and mild to moderate intellectual disability. 